\title{
Quantidade de Substância
}

\author{
Adalberto B. M. S. Bassi * \\ bassi@iqm.unicamp.br \\ Universidade Estadual de Campinas, Instituto de Química
}

\section{Informações do Artigo Resumo}

Histórico do Artigo A quantidade de substância é uma das quatro propriedades fundamentais Criado em Setembro de 2005 da termodinâmica dos meios homogêneos [1], juntamente com o volume, a energia interna e a entropia. Trata-se de um conceito lecionado desde o ensino médio, mas que, entretanto, não é tão elementar quanto possa parecer. Um aspecto nem sempre esclarecido é o fato dela se relacionar com o número de partículas de uma mesma espécie química presente no sistema, mas ao mesmo tempo variar de um modo contínuo, assim como

Palavras-Chaves as outras três propriedades fundamentais.

Quantidade de substância

Quantidade de matéria

Mol

Fundamentos da termodinâmica

Meio homogêneo

Chemkeys. Licenciado sob Creative Commons (BY-NC-SA)

\section{Objetivo}

Ressaltar os aspectos contínuo e discreto do conceito de quantidade de substância, freqüentemente confundidos nos livros didáticos.

\section{Introdução}

$\mathrm{O}$ equivalente em meio descontínuo da quantidade de substância presente num sistema é o número de partículas contidas pelo corpo correspondente ao sistema considerado ${ }^{1}$. Tal número é um adimensional inteiro positivo. Mas, porque ao se transformar o corpo em sistema considera-se que o número de partículas passe a tender para infinito, uma escala adimensional que reflita o ordenamento dos sistemas, conforme suas respectivas quantidades de substância, será o semi-eixo positivo dos reais. Para tornar dimensional esta escala, ao seu valor 1 atribui-se um sistema contendo precisamente $12 \times 10^{-3} \mathrm{~kg}$ de isótopo 12 do carbono e chama-se mol à unidade de quantidade de substância .

Isto mostra que se convencionou ser igual $12 \times 10^{-3} \mathrm{~kg}$ mol $^{-1}$ a massa molar do isótopo 12 do carbono e que "um mol é a quantidade da substância isótopo 12 do carbono

\footnotetext{
${ }^{1} \mathrm{O}$ corpo, no modelo descontínuo da natureza, corresponde ao sistema do modelo contínuo. A termodinâmica, assim como todas as ciências clássicas, pressupõe o modelo contínuo, logo todas as suas propriedades obrigatoriamente variam de forma contínua. Mas, enquanto que no passado considerava-se que a natureza é contínua e Boltzmann [2] precisava justificar sua teoria cinética dos gases como um modelo matemático que funcionava corretamente, embora adotasse a então polêmica hipótese da descontinuidade, hoje em dia considera-se que a natureza é descontínua e precisa-se justificar porque modelos contínuos produzem resultados experimentalmente corretos. Dentro da atual cultura científica, freqüentemente a melhor interpretação do significado físico de uma propriedade que varia de forma contínua é obtida explicando-se qual seria o equivalente, em meio descontínuo, desta propriedade.
} 
presente em $12 \times 10^{-3} \mathrm{~kg}$ deste material”.

Proporções mássicas bem definidas, obtidas usando-se o método de Cannizzaro [3] indicam, então, quais massas dos diversos elementos químicos devem ser associadas ao valor 1 da escala adimensional e, portanto, indicam também as massas molares destes elementos. A partir desta informação, pode-se calcular massas molares de substâncias puras e de misturas.

\section{Continuidade e descontinuidade do meio}

Note-se que, mesmo se fosse possível obter o isótopo 12 do carbono absolutamente puro, pesar exatamente 12 x 10-3 kg deste material e contar o número de átomos existentes em tal massa (três impossibilidades práticas), a indivisibilidade de qualquer um dos seus átomos (sem que a matéria resultante desta divisão deixe de ser isótopo 12 do carbono) torna extremamente improvável a ocorrência, na natureza, de precisamente $12 \times 10^{-3} \mathrm{~kg}$ de isótopo 12 do carbono. A definição de mol, portanto, é uma completa abstração mental.

Mas padrões, como o mol, precisam ser coerentes com o modelo teórico a que se referem, não necessariamente também com a natureza, porque nenhum modelo representa exatamente a natureza. $\mathrm{O}$ modelo de meio contínuo é perfeitamente coerente com o conceito de mol antes destacado, mas não é compatível com a idéia de átomo. Por isto, a bastante difundida afirmação de que o mol é "o número de átomos presentes em $12 \times 10^{-}$ ${ }^{3} \mathrm{~kg}$ de isótopo 12 do carbono" é termodinamicamente inconsistente.

A estimativa atual do número de átomos presentes naquilo que experimentalmente mais se aproxime de 12 x $10^{-3} \mathrm{~kg}$ de carbono 12 é o valor numérico da constante de Avogadro $\mathrm{N}_{\mathrm{A}}=6,0221367 \times 1023 \mathrm{~mol}^{-1}$. Isto indica que o fato da partícula não poder ser dividida, sem que se percam as características físicas e químicas da matéria, torna impossível a existência, na natureza, de quantidades de substância menores do que a contida numa partícula, cujo valor numérico, dado em mols, sempre é $\mathrm{N}_{\mathrm{A}}{ }^{-1} / \mathrm{mol}=$
$1,6605402 \times 10^{-24}$, qualquer que seja a partícula em questão (átomo, molécula, íon etc.). Note-se que, analogamente, para uma substância pura cuja massa molar seja $\mathrm{Mm}$, inexiste na natureza massa cujo valor numérico, dado em quilogramas, seja menor do que $\mathrm{M} / \mathrm{kg}=\left(\mathrm{NA}^{-1} / \mathrm{mol}\right)$ $\left(\mathrm{Mm} / \mathrm{kg} \mathrm{mol}{ }^{-1}\right)=1,6605402 \times 10-24 \mathrm{Mm} / \mathrm{kg} \mathrm{mol}^{-1} \mathrm{e}$ energia interna cujo valor seja menor do que o apresentado por esta última massa, nas condições consideradas.

Deve-se, porém, ressaltar que:

1. Tais cotas inferiores máximas não são utilizadas em termodinâmica, porque a quantidade de substância é uma propriedade extensiva aditiva dos sistemas. Os valores das propriedades extensivas de sistemas muito diminutos são obtidos por extrapolações matemáticas efetuadas em corpos, o que produz cotas inferiores máximas iguais a zero para todas as propriedades extensivas aditivas positivas. Aliás, a constante de Avogadro, NA, não pertence a teorias de meio contínuo, logo também não é utilizada em termodinâmica.

2. Numa teoria de meio descontínuo dever-se-ia substituir "precisamente $12 \times 10^{-3} \mathrm{~kg}$ de isótopo 12 do carbono" por "o múltiplo da massa do átomo de isótopo 12 do carbono mais próximo de $12 \times 10^{-3} \mathrm{~kg}$ ". Embora numericamente inócua, esta alteração seria conceitualmente importante, porque garantiria a não divisão da partícula. Por outro lado, esta alteração transformaria o mol em unidade de contagem, como por exemplo a dúzia e a centena. $\mathrm{Na}$ verdade, o mol deixaria de ser a unidade de quantidade de substância, situação esta na qual ele não atua como unidade de contagem, passando a ser uma unidade para o equivalente em meio descontínuo da quantidade de substância. Mas o valor NA = 6,0221367 x $10^{23} \mathrm{~mol}^{-}$ ${ }^{1}$ permaneceria inalterado, porque ele fornece apenas os primeiros oito dos vinte e quatro algarismos à esquerda da vírgula.

3. Existem ciências que são pontes entre teorias de meio contínuo e descontínuo, como por exemplo a teoria cinética dos gases e a termodinâmica estatística. Nestas ciências, a unidade mol pode tanto referir-se a um meio contínuo como descontínuo, conforme o caso.

\footnotetext{
${ }^{2}$ Nota do Editor: Consta do dicionário em português "quantidade de substância", mas pode-se admitir também o uso do termo "quantidade de matéria", traduzido dos documentos originais em francês. O termo "quantidade de matéria" vem do francês "quantité de matière", derivado do latim "quantitas materiae", que antigamente era usado para designar a quantidade agora denominada de "massa".
} 
Conforme afirmado, numa teoria de meio descontínuo o mol se transformaria em unidade de contagem, passando a ser uma unidade para o equivalente em meio descontínuo da quantidade de substância. Porém, uma unidade de contagem não depende do tipo de ente a ser contado. Por exemplo, se uma dúzia de lápis for um conceito correto, a princípio também será correto pensar numa dúzia de átomos e numa dúzia de galáxias. Analogamente, numa teoria de meio contínuo a unidade mol, embora não sendo uma unidade de contagem, não se restringe à quantidade de substância, podendo ser usada para medir qualquer propriedade cujo equivalente em meio descontínuo seja um número de entes, independentemente portanto destes entes serem, ou não, partículas.

Referências

1. Truesdell, C. A., Rational Thermodynamics; Springer-Verlag, 2a. ed.; 1984, p. 59-106.

2. Boltzmann, L.; Vorlesungen über Gastheorie, I; J. A. Barth, Leipzig, 1896. Tradução para o inglês efetuada por Stephen G. Brush e publicada, em 1964, pela University of California Press, sob o título "Lectures on Gas Theory, Part I". Reimpressão, em 1995, pela Dover Publications Inc., p. 26-28.

3. Mahan, B. H., University Chemistry; Addison Wesley: Reading, 3a. ed.; 1967. Esta antiga edição contém o método de Cannizzaro (p. 9) e, também, um interessante resumo histórico do desenvolvimento das idéias de massa molar e fórmula química das moléculas, não disponíveis em edições mais recentes. 